\section{(6) OPEN ACCESS}

\title{
The use of expensive technologies instead of simple, sound and effective lifestyle interventions: a perpetual delusion
}

\author{
Silvia Carlos, ${ }^{1,2}$ Jokin de Irala, ${ }^{1,2,3}$ Matt Hanley, ${ }^{1}$ Miguel Ángel Martínez-González ${ }^{1,3}$
}

${ }^{1}$ Department of Preventive Medicine and Public Health, Faculty of Medicine-Clinic University of Navarra, University of Navarra, Pamplona, Spain ${ }^{2}$ Institute for Culture and Society (ICS), Education of Affectivity and Human Sexuality, University of Navarra, Pamplona, Spain ${ }^{3}$ Centro de Investigación Biomédica en Red Fisiopatología de la Obesidad y Nutrición (CIBER-OBN), Instituto de Salud Carlos III, Madrid, Spain

\section{Correspondence to} Dr Miguel A MartínezGonzález, Departamento de Medicina Preventiva y Salud Pública, Edificio de Investigación, Universidad de Navarra, C/lrunlarrea 1. C.P., Pamplona 31008, Spain; mamartinez@unav.es

Received 3 April 2014 Revised 27 May 2014 Accepted 28 May 2014 Published Online First 24 June 2014

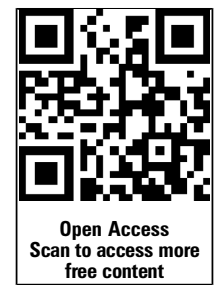

CrossMark

\begin{tabular}{|l|}
\hline To cite: Carlos S, de Irala J, \\
Hanley M, et al. J Epidemiol \\
Community Health \\
2014;68:897-904. \\
\hline
\end{tabular}

\begin{abstract}
A dangerous distortion of priorities seems to be currently apparent in the dominant approaches to major public health problems, including cardiovascular disease, diabetes, obesity, cancer and some infectious diseases. Relevant examples suggest an apparently inappropriate tendency to prioritise technocratic, partial solutions rather than confronting their true behavioural and structural determinants. Technically oriented preventive medicine often takes excessive precedence over simpler, more sensible approaches to modify lifestyles, the environment and the social structure. Structural factors (social, cultural, financial, familiar, educational, political or ideological factors) that act as determinants of individual behaviours should be effectively addressed to confront the essential causes of the most prevalent and important health problems. Some consumer-directed commercial forces seem to be increasingly driving many aspects of the current sociocultural environment, and may eventually compromise the main pursuits of public health. Population-wide strategies are needed to create a healthy sociocultural environment and to empower individuals and make themselves resistant to these adverse environmental and structural pressures. Otherwise most public health interventions will most likely end in failures.
\end{abstract}

\section{INTRODUCTION}

Has costly 'Preventive Medicine' taken precedence over simpler behavioural interventions? It makes sense to prioritise actions on the small number of behavioural factors which are the leading determinants of health. ${ }^{12}$ On the contrary, other more costly technocratic approaches seem to be playing the dominant role in current public health policies.

Emphasising medical devices over lifestyles can potentially compromise public health, ${ }^{3}$ especially when preventive technologies are applied without simultaneously addressing the behavioural or structural underlying determinants of risk.

We have selected some important public health conditions where this distortion of priorities currently seems quite conspicuous (table 1).

Table 1 includes major contributors to the global burden of disease. The headings for each row (left column) represent sound and effective alternatives. Some of these interventions are able to confront several chronic conditions at the same time. In contrast, the alternatives placed at the bottom row are the inefficient and technological solutions that seem to have been currently prioritised in many settings. ${ }^{4}$

\section{LIFESTYLE AND DIET TO PREVENT CARDIOVASCULAR DISEASE INSTEAD OF THE STATIN REDUCTIONISM}

At least $80 \%$ of premature cardiovascular deaths could be prevented simply through diet, physical activity and smoking avoidance. However, despite an increase in the use of antihypertensive and lipid-lowering drugs, the overall control of classical risk factors in the last years in Europe has been poor. Smoking continued unabated, and overweight/obesity prevalence increased dramatically. ${ }^{5}$ Cardiovascular prevention might be futile without addressing the actual underlying causes of myocardial infarction and stroke.

The 2013 updated American guidelines for cardiovascular prevention include blood cholesterol levels in all risk prediction algorithms. ${ }^{6}$ The strongest recommendation in these guidelines is the treatment with cholesterol-lowering drugs, mainly with statins (hydroxymethylglutaryl coenzyme A reductase inhibitors) for wide sectors of the population including subjects with no previous history of cardiovascular disease (CVD, ie, for primary prevention). However, the massive use of statins for primary prevention in healthy individuals is controversial. It is well known that statins do effectively reduce cardiovascular events in selected subgroups of patients with previous CVD, but the causal mechanisms leading from blood lipids to major cardiovascular clinical events need to be more thoroughly reappraised: is blood cholesterol really the major cause of CVD?; is cholesterol reduction the essential and indispensable step in CVD prevention for all kind of patients? Have we replaced the multifactorial origins of CVD by a single risk factor? It is well known that the best way to market a drug is the marketing of a disease (or one proxy of a disease). Are we reductionistically using high blood cholesterol as a commercially profitable proxy for CVD? Today, it is becoming more obvious that it is not LDL-cholesterol that is directly implicated in CVD but small, dense, type B particles generated after a high intake of sugar and processed carbohydrates. ${ }^{7-9}$ Overnutrition is related to blood lipids, and to blood pressure, resistance to insulin, inflammatory mechanisms, oxidative stress, coagulation factors and many other pathways leading to cardiovascular clinical events. A stronger focus on nutrition instead of the global oversimplification to massive statin use would have been the most sensible approach. The continually widening indication for statin prescription to more and more millions of healthy people does not seem to be scientifically justified. ${ }^{10} 11$ The US guidelines 
Table 1 Public health problems and their respective technological, behavioural or structural solutions

\begin{tabular}{|c|c|c|c|c|c|c|}
\hline \multirow[b]{2}{*}{ Preventive measure } & \multicolumn{6}{|c|}{ Public health issue } \\
\hline & All cancers & Lung cancer & $\begin{array}{l}\text { Cervical } \\
\text { cancer }\end{array}$ & $\begin{array}{l}\text { Cardiovascular } \\
\text { disease }\end{array}$ & Type 2 diabetes & Obesity \\
\hline \multicolumn{7}{|c|}{ Not sufficiently prioritised lifestyle interventions } \\
\hline Smoking avoidance & $\checkmark$ & $\checkmark$ & $\checkmark$ & $\checkmark$ & $\checkmark$ & \\
\hline Alcohol avoidance & $\checkmark$ & & & & & \\
\hline Eat less & $\checkmark$ & & & $\checkmark$ & $\checkmark$ & $\checkmark$ \\
\hline Weight control & $\checkmark$ & & & $\checkmark$ & $\checkmark$ & $\checkmark$ \\
\hline Low energy density diets & & & & & $\checkmark$ & $\checkmark$ \\
\hline Mediterranean-type diet & $\checkmark$ & & & $\checkmark$ & $\checkmark$ & $\checkmark$ \\
\hline$\uparrow$ Fruits and vegetables & $\checkmark$ & $\checkmark$ & & $\checkmark$ & $\checkmark$ & $\checkmark$ \\
\hline$\uparrow C i s$-unsaturated fats & & & & $\checkmark$ & & \\
\hline$\uparrow C i s$-unsaturated fish & & & & $\checkmark$ & & \\
\hline$\downarrow$ Added sugars & & & & $\checkmark$ & $\checkmark$ & $\checkmark$ \\
\hline$\downarrow$ Trans fats & & & & $\checkmark$ & $\checkmark$ & $\checkmark$ \\
\hline$\downarrow$ Red meats & $\checkmark$ & & & $\checkmark$ & $\checkmark$ & $\checkmark$ \\
\hline$\downarrow$ Refined cereals & & & & & $\checkmark$ & $\checkmark$ \\
\hline Physically active lifestyle & $\checkmark$ & $\checkmark$ & & $\checkmark$ & $\checkmark$ & $\checkmark$ \\
\hline Pap-screening & & & $\checkmark$ & & & \\
\hline Reduction of sexual partners & & & $\checkmark$ & & & \\
\hline Delayed sexual debut & & & $\checkmark$ & & & \\
\hline Character education* & $\checkmark$ & $\checkmark$ & $\checkmark$ & $\checkmark$ & $\checkmark$ & $\checkmark$ \\
\hline \multicolumn{7}{|c|}{ Not sufficiently prioritised structural approaches } \\
\hline Smoke-free spaces & $\checkmark$ & $\checkmark$ & $\checkmark$ & $\checkmark$ & $\checkmark$ & \\
\hline Raise tobacco prices & $\checkmark$ & $\checkmark$ & $\checkmark$ & $\checkmark$ & $\checkmark$ & \\
\hline Air pollution control & $\checkmark$ & $\checkmark$ & & $\checkmark$ & & \\
\hline Healthy food affordability & $\checkmark$ & $\checkmark$ & & $\checkmark$ & $\checkmark$ & $\checkmark$ \\
\hline Trans-fats banning & & & & $\checkmark$ & $\checkmark$ & $\checkmark$ \\
\hline Walking and cycle ways & $\checkmark$ & $\checkmark$ & & $\checkmark$ & $\checkmark$ & $\checkmark$ \\
\hline Healthy school meals & & & & $\checkmark$ & $\checkmark$ & $\checkmark$ \\
\hline$\downarrow$ Serving size in restaurants & $\checkmark$ & & & $\checkmark$ & $\checkmark$ & $\checkmark$ \\
\hline$\downarrow$ Added sugars & & & & $\checkmark$ & $\checkmark$ & $\checkmark$ \\
\hline Sexual attitudes and beliefs & & & $\checkmark$ & & & \\
\hline Cultural change (social norms) & $\checkmark$ & $\checkmark$ & $\checkmark$ & & $\checkmark$ & $\checkmark$ \\
\hline $\begin{array}{l}\text { Expensive and dubious technological } \\
\text { 'solutions' }\end{array}$ & $\begin{array}{l}\text { Genetic } \\
\text { testing }\end{array}$ & $\begin{array}{l}\text { Screening (low-dose } \\
\text { CT) }\end{array}$ & HPV vaccine & Statins & $\begin{array}{l}\text { Metformin, } \\
\text { thiazolidindiones }\end{array}$ & $\begin{array}{l}\text { Antiobesity } \\
\text { drugs }\end{array}$ \\
\hline
\end{tabular}

as well as the newly updated UK guidelines, ${ }^{12}$ seem to assume that the unique solution to the CVD pandemic is the replacement of CVD by a proxy (blood cholesterol) and therefore justify a blanket-wide use of statins. This oversimplification has provoked ample criticisms. 81013

Do we need to prescribe statins or 'polypills' to more than $30 \%$ of the general adult population for CVD prevention when we already know that $80 \%$ of CVD events can be prevented with simple dietary and non-dietary lifestyle measures? ${ }^{14-17}$ As the large PREvención con DIeta MEDiterránea (PREDIMED) primary prevention nutritional trial showed, simple dietary interventions can prevent many different cardiovascular problems. Indeed, only a modest increment in the adherence to the Mediterranean diet supplemented with extra virgin olive oil $(100 \%$ fat) or with nuts ( $>50 \%$ fat) obtained a $30 \%$ relative reduction in major cardiovascular events (stroke, myocardial infarction, cardiovascular death) ${ }^{18} \quad 19$ and also attained other cardiovascular benefits in primary prevention. ${ }^{20} 21$ Improved adherence to a high-quality dietary pattern has the additional benefit of enjoying palatable foods and will allow many more people to live longer without any need of recommending low-fat diets or using pharmacological solutions which are not exempt from side effects. ${ }^{15}$ Yet, even though light to moderate alcohol intake might reduce cardiovascular mortality, ${ }^{22}$ being physically active and eating a healthier diet can be more effective than drinking a low dose of alcohol, which may have other undesirable effects. $^{2} 23$

\section{MEDICATION VERSUS LIFESTYLE IN DIABETES PREVENTION}

Type 2 diabetes (T2D) is likely to become the next major epidemic largely as a result of the current obesity pandemic. T2D will affect more than $10 \%$ of the adult population in many countries during the next two decades, with a projected increase of $55 \%$ by $2035 .^{24} 25 \mathrm{~T} 2 \mathrm{D}$ is also increasing in the youth. ${ }^{26}$

However, T2D is largely preventable. ${ }^{27}$ Up to $91 \%$ of T2D cases could be prevented by relatively modest lifestyle changes. $^{28}$ Therefore global growing rates of T2D represent a profound humiliation for public health. Randomised controlled trials and longitudinal observational studies have confirmed that 
dietary changes combined with non-dietary lifestyle modifications can have a long-term effect on T2D prevention. ${ }^{29} 30$ The large Diabetes Prevention Program trial (figure 1) in 2002 showed that a lifestyle intervention based on dietary changes and on physical activity performed better than the metforminmedicalised option: 58\% (lifestyle) versus 31\% (metformin) relative reduction in risk over 3.2 years of follow-up, and $34 \%$ versus $18 \%$, respectively, at 10 years of follow-up. ${ }^{31} 32$ Furthermore, metformin efficacy was only limited to subjects with a body mass index $>35 \mathrm{~kg} / \mathrm{m}^{2}$. ${ }^{31}$ The outstanding results of this landmark trial continue today to support the superiority of lifestyle interventions in comparison with pharmacological approaches to prevention. This is also true for realistic improvements on different components of the metabolic syndrome and on the atherogenic dyslipidaemia frequently observed in patients with diabetes or prediabetes. These nutritional improvements help to reduce T2D and cardiovascular risk in people with impaired glucose tolerance. ${ }^{33}{ }^{34}$ Moreover, recent evidence supports that participants in nutrition intervention studies appear to sustain the dietary changes over time. ${ }^{35}$ Additionally, pharmacological approaches to prevention may have adverse effects. Metformin has a good record for effectiveness and safety, but the potential adverse effects of other medications used against diabetes (eg, thiazolidinediones) ${ }^{36-38}$ add reasons for caution. The alarming worldwide prevalence of undiagnosed T2D, with almost half of all cases still not detected ${ }^{25}$ is a good reason to use preventive population-wide dietary and lifestyles strategies. Thus, lower-cost healthy lifestyles should be the priority for the global prevention of T2D. ${ }^{27} 2839$ The Mediterranean diet, with a millenary history of no harm, is beneficial for primary cardiovascular prevention, ${ }^{40}$ and to reduce T2D risk. ${ }^{41}$ Indeed, the large PREDIMED randomised trial has also recently shown that changes in the overall dietary pattern with a long-term (up to 7-year follow-up) adoption of the Mediterranean diet can reduce the risk of $\mathrm{T} 2 \mathrm{D}$ among persons at high cardiovascular risk. $^{30}$

Another essential strategy for T2D prevention is physical activity, because physical inactivity is responsible of around $27 \%$ of T2D cases. The promotion of physical activity has been included in many international clinical guidelines for the

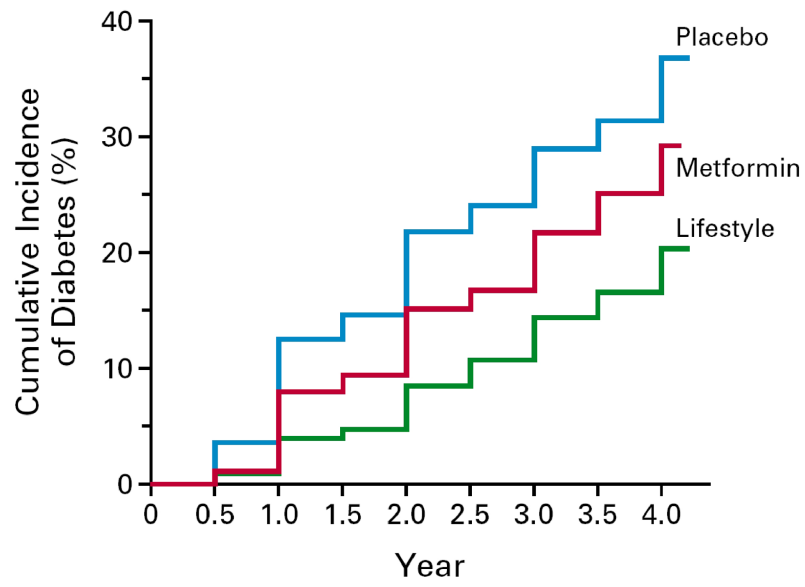

Figure 1 Cumulative incidence of type 2 diabetes in the Diabetes Prevention Program trial $(n=3234) . p<0.001$ for all comparisons. Among participants with $\mathrm{BMI}<35 \mathrm{~kg} / \mathrm{m}^{2}(\mathrm{n}=2040)$, no significant differences were found between metformin and placebo. 'From (Knowler et $a l^{\beta 1}$ Copyright (2002) Massachusetts Medical Society. Reprinted with permission from Massachusetts Medical Society).' prevention of major chronic diseases. ${ }^{42} 43$ The new fact sheet of the WHO recommends that adults should do at least $150 \mathrm{~min} /$ wk of physical activity of moderate intensity. ${ }^{44}$ However, we are still far from reaching this recommendation and global levels of physical activity keep falling. ${ }^{45}{ }^{46}$ Public health policies need to implement effective promotion programmes to make physical activity accessible and attractive for whole populations. An active lifestyle can be promoted with correct and specific instructions to be included in the routines of the general population at large. Personal, social and environmental contexts have to be considered to achieve this purpose. ${ }^{43}$

The current absence of large randomised trials to assess the benefits of physical activity using hard clinical end points is somewhat surprising. Large randomised trials to assess the longterm effects of physical activity are badly needed.

\section{THE MIRAGE OF ANTIOBESITY DRUGS}

Worldwide, around $35 \%$ of the adult population are overweight and $12 \%$ are obese. ${ }^{47} 48$ The prevalence of overweight and obese children and adolescents is also rapidly increasing, ${ }^{49-51}$ with an expected 9.1\% worldwide prevalence in $2020 .^{52-54}$ One temptation is to seek 'technological' or pharmaceutical solutions which allow to eat calorie-dense foods ad libitum and still not become obese. But the story of what has happened with several seemingly 'magic' antiobesity drugs is instructive: some were rejected by the food and drug administration (FDA), others were withdrawn from the market or are still awaiting decisions because of safety concerns. ${ }^{55-57}$ Although it is easier for doctors and patients to turn to a pill than to address behaviour, we likely do not need more antiobesity drugs trials but a change of paradigm. ${ }^{58} 59$ The problem is that our culture, which advertises how to eat more, resists the simple message 'eat less'. ${ }^{3}$ An obesogenic environment is a strong determinant of the current obesity epidemic. However, not all subjects exposed to this environment become obese. Susceptible individuals become obese, whereas resistant subjects remain lean. A strong hedonistic attraction to palatable foods and to overeating has proven to be a decisive factor to explain weight gain in an obesogenic environment. ${ }^{60}$ Given the actual prevalence of obesity and its worrisome health consequences, the population would benefit more from being turned towards attractive and high-quality lighter meals, with an adequate proportion of the evidence-based recommended foods.

\section{CANCER: COMPUTED TOMOGRAPHY SCREENING}

The development of the 'omics' sciences (genomics, transcriptomics, proteomics, metabolomics) has contributed to overshadowing the fact that it is not genetic predisposition but social, environmental and behavioural factors which cause most cancers. $^{2}$ 61-63 The good news is that these environmental and behavioural factors are modifiable. ${ }^{64}$

Twelve forms of cancer are the major global contributors to deaths by neoplasia (figure 2). The cancer which causes most deaths-lung cancer-is the one that could be most easily and cost-effectively prevented, just by altering behavioural (active smoking) and environmental (passive smoking) factors. ${ }^{65-67}$

Expensive screening of lung cancer with low-dose CT has been recently endorsed by the United States Preventive Services Task Force (USPSTF) in high-risk subjects because of their tobacco smoking history. ${ }^{68}$ However, this approach, which has important harms associated with false positive results, overdiagnoses and radiation, cannot prevent most lung cancer-related deaths, as it results in only a $16 \%$ reduction in lung cancer mortality. ${ }^{68}$ In comparison, a near $40 \%$ reduction in lung cancer 
Figure 2 Major cancers in the world. Projections of mortality from the most frequent cancers for 2015. Source: WHO. Mortality and global health estimates. Cause-specific mortality. Projections of number of deaths for 2015-2030. http://apps.who.int/gho/ data/node.main.PROJNUMWORLD? lang=en (accessed 17 Mar 2014).

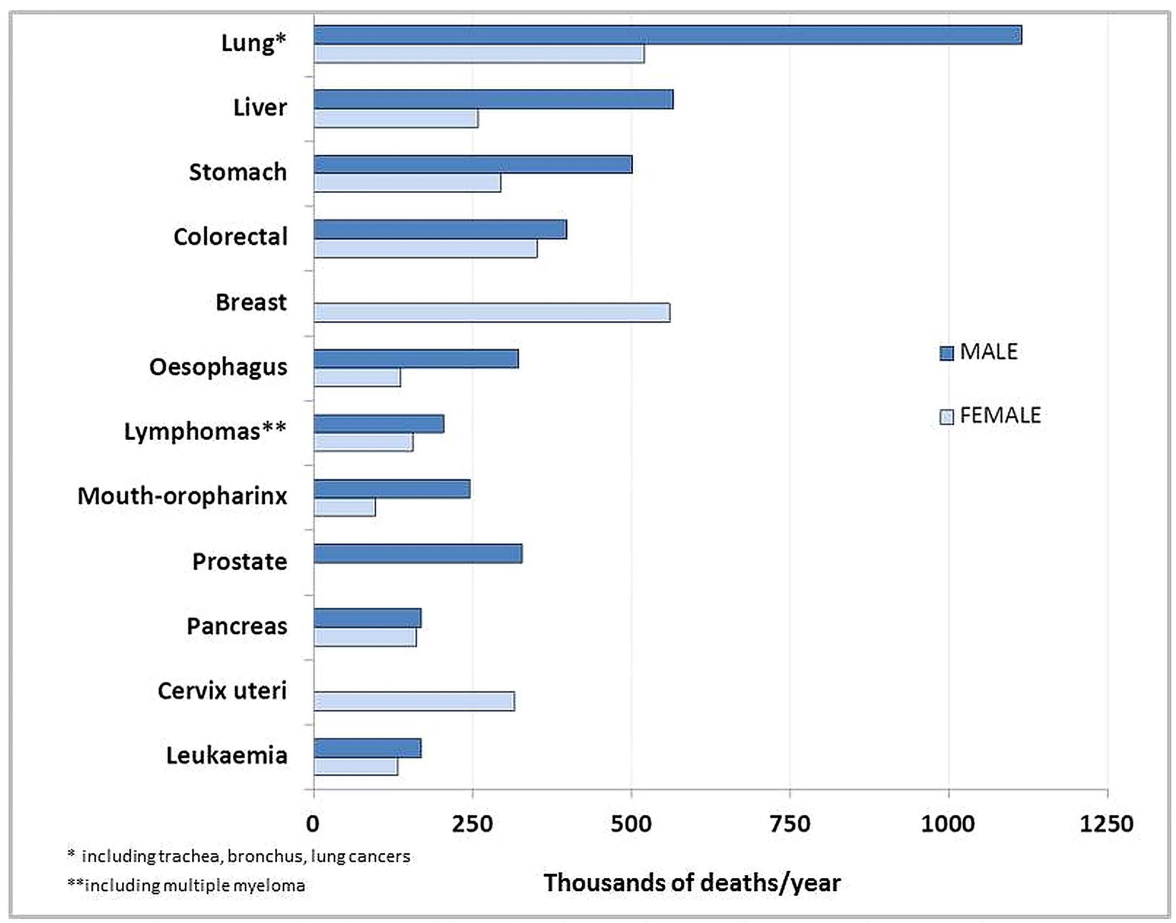

deaths was already attributed to decreases in smoking in the past century $^{69}$ and a $90 \%$ risk reduction for overall smoking-associated mortality has been recently estimated. ${ }^{70}$

The lure of a high tech screening device can overshadow the fact that billions of cigarettes are still smoked worldwide every day and that the number of smokers is increasing in many countries. ${ }^{69} 71$ Nineteen types of cancer are attributable to tobacco smoking. ${ }^{63}$ Is it not worthy to tackle, as the first priority, this common cause of a largely lifestyle-associated disease projected to keep increasing? ${ }^{69}$ Tobacco retail prices remain too low in some countries and although tobacco has become less affordable in some countries it is now more affordable in many others (figure 3). Sadly, the global burden of disease attributable to tobacco smoking (including secondhand smoke) has changed little. $^{2}$

Screening costs were not considered in the USPSTF and other guidelines ${ }^{67} 68$ and screening is not an alternative to smoking cessation but an additional intervention. Therefore, governmental actions must focus first on tobacco-avoiding policies. ${ }^{72-79}$ The priority in lung cancer prevention is not screening

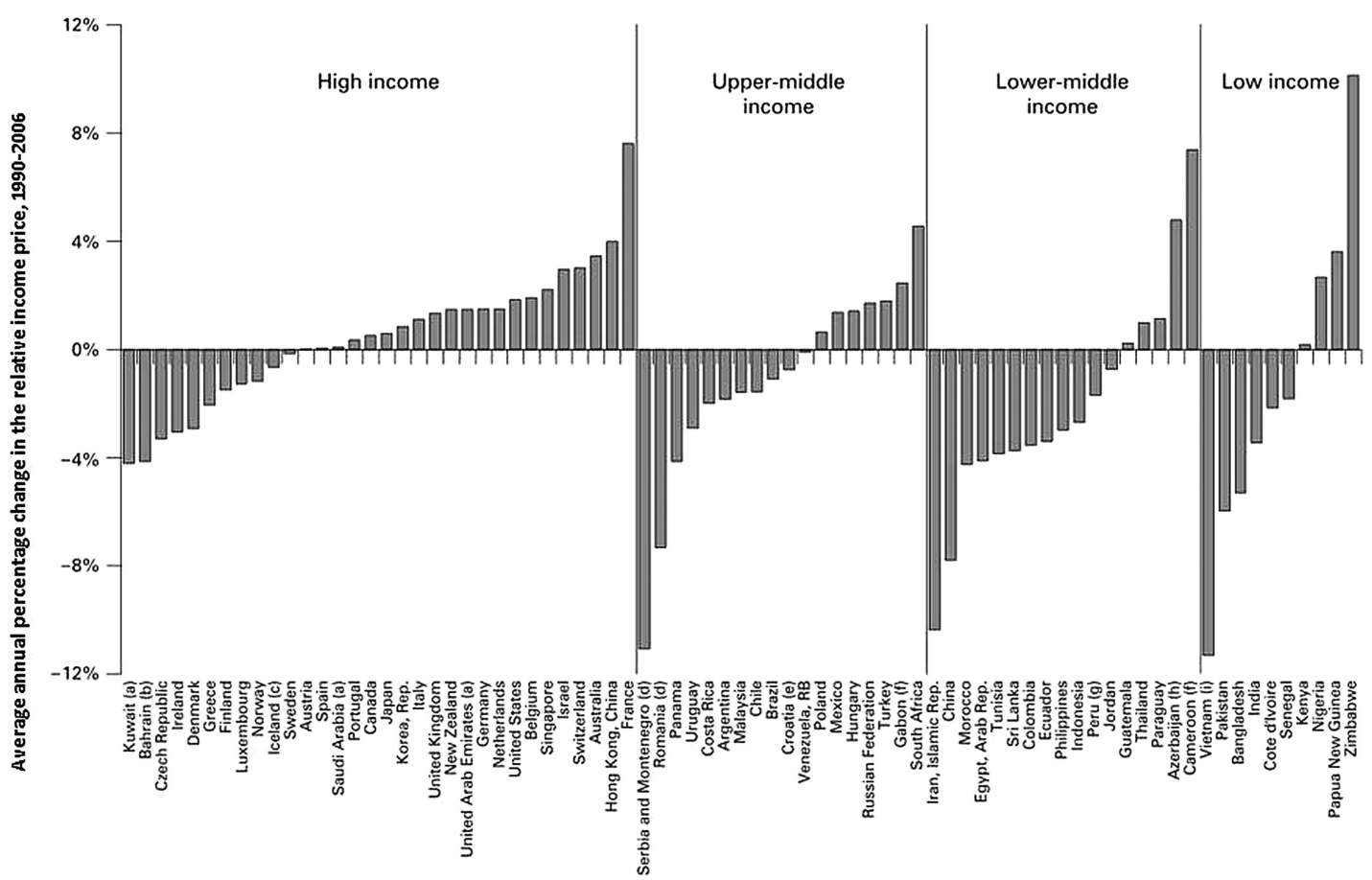

(a) 1995-2005, (b) 1990-2005, (c) 1999-2006, (d) 1994-2006, (e) 1998-2002, (f) 1991-2002, (g) 1991-2006, (h) 1998-2006, (i) 1993-2005.

Figure 3 Cigarette affordability growth rates, 1990-2006. The countries are sorted by income status and then by growth in affordability. Positive growth in relative income price means that cigarettes have become less affordable. Reproduced with permission from Tob Control 2009;18:167-75. 
(secondary prevention) but complete avoidance of smoking (primary prevention) and even primordial prevention to completely eradicate the existence of smoking in our societies and prevent the initiation of smoking for all members of future generations. $^{616980}$

The above-mentioned non-communicable diseases (NCDs) are largely preventable by addressing common lifestyle determinants (unhealthy diet, physical inactivity and tobacco use). ${ }^{81} 82$ A recent modelling study has analysed the potential impacts in NCD mortality of reducing six selected preventable risk factors (tobacco, alcohol, salt intake, obesity, raised blood pressure and raised blood glucose). It has concluded that achieving the reduction of these six risk factors will decrease the probability of premature deaths from 2010 to 2025 by 33\% from CVDs, $12 \%$ from lung cancer and 5\% from diabetes. ${ }^{83}$ Therefore, sociological and cultural issues need to be fully addressed and require educational and structural responses. ${ }^{84-89}$ From an equity perspective, environments should make the healthier choice the easiest choice so that prevention becomes accessible, available and affordable to all sectors of the population. ${ }^{5758} 90-94$ On the other hand, energy-dense fast foods, sugar sweetened beverages, smoking and sedentary lifestyles should be made the harder options. These are not sweet truths for some food or beverage corporations or for the technocratic business, ${ }^{39}{ }^{95}$ but they are indeed the priorities for public health.

\section{HPV VACCINE: THE GLAMOUR OF TECHNOPREVENTION}

Also, some approaches to the prevention of communicable diseases have apparently forgotten the need to give appropriate priority to lifestyle interventions and heavily relied on technocratic solutions. Universal policies to vaccinate girls against human papillomavirus (HPV) were adopted very rapidly during 2006-2009. The technical merits of this vaccine should be acknowledged and appreciated. However, many issues on this publicly funded mass vaccination remain unsolved: its coverage and affordability for the most vulnerable and affected countries, its long-term effectiveness and the uncertain-though potential -replacement of the vaccine-targeted strains with other highrisk types. ${ }^{96-98}$ Strong conflicts of interest are another reason for concern as available trials were sponsored by the manufacturers.

Affordability and an adequate coverage with complete vaccine regimens are two essential components for HPV vaccination programmes success. The vaccination programmes have mostly been implemented and publicly funded in higher-income countries although most of them have very low rates of HPV-related diseases. ${ }^{99}$ The rapid introduction of this publicly funded vaccine in Spain does not match the epidemiological needs of the country because there is no epidemic of cervical cancer in Spain whatsoever. On the contrary, mortality and incidence of cervical cancer are very low and show a decreasing trend in Spanish women (figure 4).

In developed countries the coverage and effectiveness are lower for girls at higher risk. ${ }^{100}$ In addition, very few developing countries have introduced HPV vaccine into their national programmes although the burden of HPV-related diseases is highest there. At the current cost, mass vaccination is unaffordable in low-income and middle-income countries. In Africa, although several countries are implementing HPV vaccine demonstration projects, only Rwanda initiated a countrywide vaccination, after receiving a donation of several million vaccine doses from the manufacturer. ${ }^{101} 102$ The Global Alliance for Vaccines and Immunisation has offered some of the world's poorest countries the quadrivalent vaccine at $\$ 4.50 /$ dose. But overall, vaccination programmes will still be prohibitively expensive and their widespread implementation will not probably be sustainable.

Moreover, vaccine efficiency heavily depends on an adequate coverage with the complete regimen ${ }^{103}$ and we do not yet know the long-term efficacy even when a high coverage is reached. Today, HPV vaccine coverage is still quite low in many countries, including economically developed countries such as the USA, where coverage for adolescent girls with all three doses was $33.4 \%$ in 2012 .

Is the vaccination supplanting the need to combat the major risk factors? Why has an expensive and only partially preventive measure been rapidly introduced while other well-known and sufficiently proven measures been downgraded?

The rates of cervical cancer in a country are highly dependent on the availability of and women compliance with screening programmes. HPV infection strongly depends on partners' number and other sexual risk behaviours. Long-term primary prevention strategies are needed, which include structural interventions and sexual education with correct and complete information to increasing awareness about the basic facts of HPV infection. These simple, affordable and sustainable measures are absolutely essential for cancer prevention, especially in developing countries.

\section{RISK COMPENSATION}

If preventive strategies focus preferentially on glamorous technological options, apart from the problems herein described, another important unexpected consequence is risk compensation. People may consider themselves healthy enough when they eat foods labelled as low-energy/low-fat, take the prescribed pills and vaccines or attend the recommended screening programmes no matter if they keep sedentary, adhere to lowquality food patterns, smoke or have many other dietary and non-dietary risk behaviours. For example, the new USPSTF guidelines for lung cancer screening notice that people may keep on smoking thinking that screening programmes can reduce their smoking-related risks. ${ }^{68}$ Believing in a new preventive technology may lead to a dangerous sense of immunity. The available evidence is not fully consistent, but risk compensation has also been associated with HPV vaccine acceptability and this affects vaccine coverage and consequently, effectiveness and efficiency. ${ }^{969799103}$ Therefore, it is important that preventive messages address the specific target population groups in which these biomedical strategies are to be recommended so that no erroneous beliefs turn up. Always, apart from the high-risk subjects, the general population needs to be correctly informed because population-wide strategies to promote healthy lifestyles are frequently the most cost-effective option. ${ }^{57}$

\section{COMMON BUILDING BLOCKS: EMPOWERMENT AND STRUCTURAL CHANGES}

Screening, diagnosis and treatment represent real breakthroughs and have accounted for tremendous advances in health status. In fact, the technological preventive interventions mentioned in this paper can surely have some role and should be applied when they are appropriately justified. However, the unprecedented and continuous increase in the use of pharmacological/ technological approaches, confirms that these approaches might not be adequate to manage the complex pathogenesis and consequences of chronic diseases. In addition, the partially successful pharmacological/technological approaches are responsible for inevitable and unsustainable increases in health expenditures; hence, alternative lifestyle and dietary strategies should be given a sufficiently high priority. A body of sound epidemiological evidence exists to support the effectiveness of diet and 
Figure 4 Trends of estimated cervical cancer mortality rates in Spanish regions (1975-2004). Vaccination in Spain began in 2007. Reproduced with permission from Elsevier. Original article: Rodríguez-Rieiro et $\mathrm{al}^{106}$.

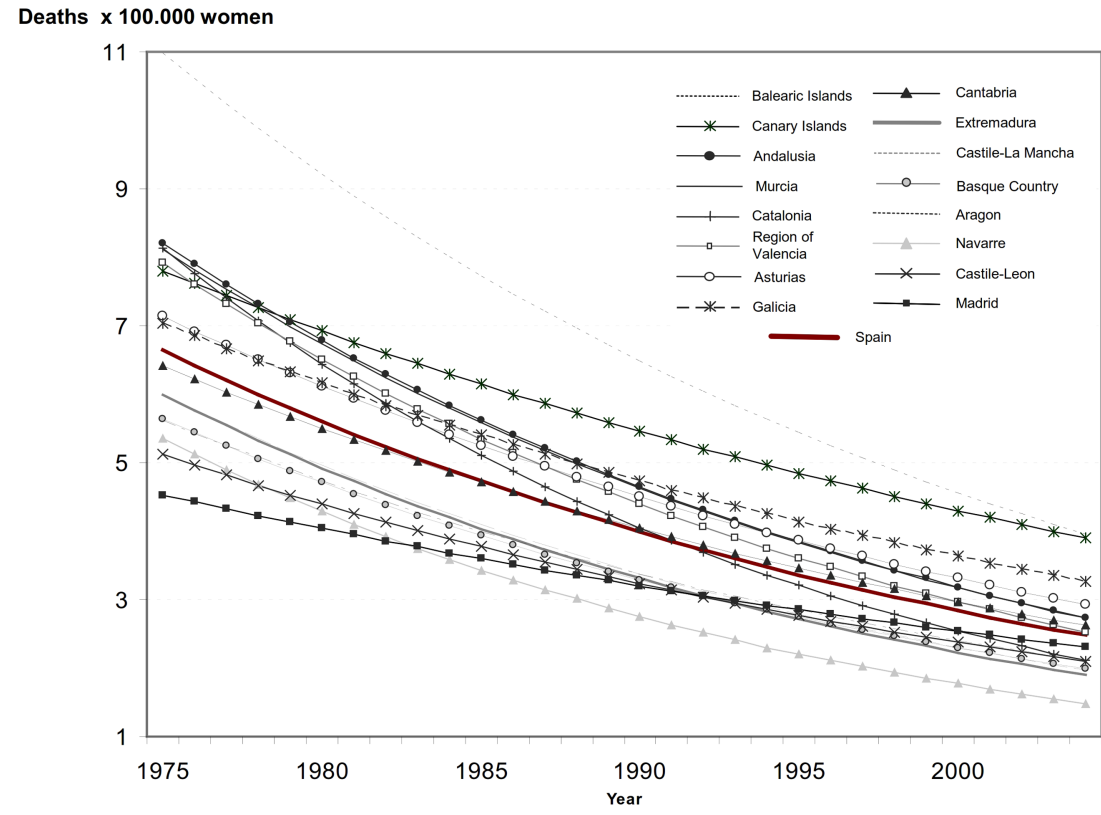

We acknowledge that the needed cultural change is not easy. Cultivating an environment where healthier options are encouraged requires entering in decision arenas and counteracting commercially driven forces investing millions in advertising and opinion-making. Therefore, it does not always conform with the 'politically correct' positions and it is far from cheap and simple to achieve. However, if sociocultural and normative changes are attained, they will lead to dramatic reversals of epidemics. We do not need to shape individuals' minds to fit our increasingly unhealthy societies but we need to redesign the environment to fit our populations' health.

The implementation of all the strategies proposed here should be considered a priority for public health.

\section{What is already known on this subject?}

- Reducing some of the main preventable risk factors described here (tobacco, alcohol, salt intake, high blood pressure and blood glucose and diabetes) will lead to higher reductions in probability of death compared with current trends with no additional action ( $22 \%$ in men and $19 \%$ in women) and even more in case of early action $(24 \% \text { and } 21 \%)^{83}$

\section{What this study adds?}

- The new guidelines for cardiovascular prevention can be misinterpreted and lead to an excessive use of statins; statin use should be decided depending on individual circumstances.

- The growing trends in type 2 diabetes (T2D) prevalence represent a humiliation for public health because T2D is easily prevented with diet and lifestyle.

- The key message for obesity prevention is "to eat less".

- Screening for lung cancer is probably inefficient and not affordable and may distort the true priority: smoking avoidance.

- Technoprevention with HPV vaccination can backfire without addressing the true underlying behavioural determinants of risk. 
Contributors All authors have: Made substantial contributions to the conception or design of the work; Drafted the work or revised it critically for important intellectual content; Approved the final version to be published; and Agreed to be accountable for all aspects of the work in ensuring that questions related to the accuracy or integrity of any part of the work are appropriately investigated and resolved.

\section{Competing interests None.}

Provenance and peer review Commissioned; externally peer reviewed.

Open Access This is an Open Access article distributed in accordance with the Creative Commons Attribution Non Commercial (CC BY-NC 3.0) license, which permits others to distribute, remix, adapt, build upon this work non-commercially, and license their derivative works on different terms, provided the original work is properly cited and the use is non-commercial. See: http://creativecommons.org/ licenses/by-nc/3.0/

\section{REFERENCES}

1 US Burden of Disease Collaborators. The state of US health, 1990-2010: burden of diseases, injuries, and risk factors. JAMA 2013:310:591-608.

2 Lim SS, Vos T, Flaxman AD, et al. A comparative risk assessment of burden of disease and injury attributable to 67 risk factors and risk factor clusters in 21 regions, 1990-2010: a systematic analysis for the Global Burden of Disease Study 2010. Lancet 2012;380:2224-60.

3 Anonimous. The catastrophic failures of public health. Lancet 2004;363:745.

4 Brezis M, Wiist WH. Vulnerability of health to market forces. Med Care 2011;49:232-9

5 Nichols M, Townsend N, Scarborough P, et al. European Cardiovascular Disease Statistics 2012. Sophia Antipolis: European Heart Network and European Society of Cardiology, 2012.

6 Stone NJ, Robinson J, Lichtenstein AH, et al. 2013 ACC/AHA Guideline on the Treatment of Blood Cholesterol to Reduce Atherosclerotic Cardiovascular Risk in Adults: A Report of the American College of Cardiology/American Heart Association Task Force on Practice Guidelines. Circulation 2013 Nov 7. pii: S0735-1097(13) 06028-2. doi:10.1016/j.jacc.2013.11.002

7 Malhotra A. Saturated fat is not the major issue. BMJ 2013;347:f6340.

8 Sinatra ST, Teter BB, Bowden J, et al. The saturated fat, cholesterol, and statin controversy a commentary. J Am Coll Nutr 2014;33:79-88.

9 Singh GM, Danaei G, Farzadfar F, et al. The age-specific quantitative effects of metabolic risk factors on cardiovascular diseases and diabetes: a pooled analysis. PLoS One 2013;8:e65174.

10 loannidis JP. More than a billion people taking statins?: Potential implications of the new cardiovascular guidelines. JAMA 2014;311:463-4.

11 Pencina MJ, Navar-Boggan AM, D'Agostino RB Sr, et al. Application of new cholesterol guidelines to a population-based sample. N Engl I Med 2014;370:1422-31.

12 Anonimous. Statins for millions more? Lancet 2014;383:669.

13 Ridker PM, Cook NR. Statins: new American guidelines for prevention of cardiovascular disease. Lancet 2013:382:1762-5.

14 Reiner Z. Polypill is not a 'vaccine-like' solution for primary cardiovascular disease prevention in all parts of the world. J Epidemiol Community Health 2013;67:981-2.

15 Perlmutter D, Golomb B, Sinatra S, et al. Appropriate clinical use of statins: a discussion of the evidence, scope, benefits, and risk. Altern Ther Health Med 2013;19(Suppl 1):14-25.

16 World Health Organization. Cardiovascular diseases. Fact sheet No317. Updated March 2013.

17 Mascitelli L, Goldstein MR. Statin and exercise prescription. Lancet 2013;381:1622.

18 Martínez-González MÁ, Corella D, Salas-Salvadó J, et al. Cohort profile: design and methods of the PREDIMED study. Int J Epidemiol 2012;41:377-85.

19 Estruch R, Ros E, Salas-Salvadó J, et al. Primary prevention of cardiovascular disease with a Mediterranean diet. N Eng/ J Med 2013;368:1279-90.

20 Ruiz-Canela M, Estruch R, Corella $D$, et al. Association of Mediterranean diet with peripheral artery disease: the PREDIMED randomized trial. JAMA 2014;311:415-17.

21 Martínez-Gonzalez MA, Toledo E, Aros F, et al. Extra-virgin olive oil consumption reduces risk of atrial fibrillation: the PREDIMED trial. Circulation 2014 Apr 30. [Epub ahead of print]

22 Gea A, Bes-Rastrollo M, Toledo E, et al. Mediterranean alcohol-drinking pattern and mortality in the SUN (Seguimiento Universidad de Navarra) Project: a prospective cohort study. Br J Nutr 2014;111:1871-80.

23 Testino G, Patussi V, Scafato E, et al. Alcohol, cardiovascular disease and cancer. Alcohol Alcohol 2013;48:627-8.

24 Shaw JE, Sicree RA, Zimmet PZ. Global estimates of the prevalence of diabetes for 2010 and 2030. Diabetes Res Clin Pract 2010;87:4-14.

25 Beagley J, Guariguata L, Weil C, et al. Global estimates of undiagnosed diabetes in adults for 2013. Diabetes Res Clin Pract 2014;103:150-60.
26 Zimmet PZ, Magliano DJ, Herman WH, et al. Diabetes: a 21st century challenge. Lancet Diabetes Endocrinol 2014;2:56-64.

27 Ley SH, Hamdy O, Mohan V et al. Prevention and management of type 2 diabetes: dietary components and nutritional strategies. Lancet 2014;383:1999-2007.

$28 \mathrm{Hu} F \mathrm{~B}$, Manson JE, Stampfer MJ, et al. Diet, lifestyle, and the risk of type 2 diabetes mellitus in women. $N$ Eng J Med 2001;345:790-7.

29 Danaei $G$, Pan A, Hu FB, et al. Hypothetical midlife interventions in women and risk of type 2 diabetes. Epidemiology 2013;24:122-8.

30 Salas-Salvadó J, Bulló M, Estruch $R$, et al. Prevention of diabetes with Mediterranean diets: a subgroup analysis of a randomized trial. Ann Intern Med 2014;160:1-10.

31 Knowler WC, Barrett-Connor E, Fowler SE, et al.; Diabetes Prevention Program Research Group. Reduction in the incidence of type 2 diabetes with lifestyle intervention or metformin. N Engl J Med 2002;346:393-403.

32 Knowler WC, Fowler SE, Hamman RF, et al.; Diabetes Prevention Program Research Group. 10-year follow-up of diabetes incidence and weight loss in the Diabetes Prevention Program Outcomes Study. Lancet 2009;374:1677-86.

33 Florez H, Temprosa MG, Orchard TJ, et al. Metabolic syndrome components and their response to lifestyle and metformin interventions are associated with differences in diabetes risk in persons with impaired glucose tolerance. Diabetes Obes Metab 2014;16:326-33.

34 Goldberg R, Temprosa M, Otvos J, et al. Lifestyle and metformin treatment favorably influence lipoprotein subfraction distribution in the Diabetes Prevention Program. J Clin Endocrinol Metab 2013;98:3989-98.

35 Davis NJ, Ma Y, Delahanty LM, et al. Predictors of sustained reduction in energy and fat intake in the Diabetes Prevention Program Outcomes Study intensive lifestyle intervention. J Acad Nutr Diet 2013;113:1455-64.

36 Cleland JG, Atkin SL. Thiazolidinediones, deadly sins, surrogates, and elephants. Lancet 2007;370:1103-4.

37 Hiatt WR, Kaul S, Smith RJ. The cardiovascular safety of diabetes drugs-insights from the rosiglitazone experience. N Engl J Med 2013;369:1285-7.

38 Tucker ME. FDA panel advises easing restrictions on rosiglitazone. BMJ 2013;346: f3769.

39 Zhang $\mathrm{P}$, Zhang $\mathrm{X}$, Brown J, et al. Global healthcare expenditure on diabetes for 2010 and 2030. Diabetes Res Clin Pract 2010;87:293-301.

40 Martinez-Gonzalez MA, Bes-Rastrollo M. Dietary patterns, Mediterranean diet, and cardiovascular disease. Curr Opin Lipidol 2014;25:20-6.

41 Salas-Salvadó J, Martinez-González MÁ, Bulló M, et al. The role of diet in the prevention of type 2 diabetes. Nutr Metab Cardiovasc Dis 2011;21(Suppl 2): B32-48.

42 Hamer M. Physical activity and health: MMXII. J Epidemiol Community Health 2012;66:665-6.

43 Heath GW, Parra DC, Sarmiento OL, et al. Evidence-based intervention in physical activity: lessons from around the world. Lancet 2012:380:272-81.

44 World Health Organization. Physical activity. Fact sheet No 384. February 2014.

45 Hallal PC, Andersen LB, Bull FC, et al.; Lancet Physical Activity Series Working Group. Global physical activity levels: surveillance progress, pitfalls, and prospects. Lancet 2012;380:247-57.

46 Sibai AM, Costanian C, Tohme R, et al. Physical activity in adults with and without diabetes: from the 'high-risk' approach to the 'population-based' approach of prevention. BMC Public Health 2013;13:1002.

47 Stevens GA, Singh GM, Lu Y, et al. National, regional, and global trends in adult overweight and obesity prevalences. Popul Health Metr 2012:10:22.

48 World Health Organization. Obesity and overweight. Fact sheet No 311 Updated March 2013.

49 Bibiloni MD, Pons A, Tur JA. Prevalence of overweight and obesity in adolescents: a systematic review. ISRN Obes 2013;2013:392747.

50 Gordon-Larsen P, Wang H, Popkin BM. Overweight dynamics in Chinese children and adults. Obes Rev 2014;15(Suppl 1):37-48.

51 Willett WC, Stampfer MJ. Current evidence on healthy eating. Annu Rev Public Health 2013;34:77-95.

52 de Onis $\mathrm{M}$, Blössner $\mathrm{M}$, Borghi E. Global prevalence and trends of overweight and obesity among preschool children. Am J Clin Nutr 2010;92:1257-64.

53 Ogden CL, Carroll MD, Kit BK, et al. Prevalence of childhood and adult obesity in the United States, 2011-2012. JAMA 2014;311:806-14.

54 Cunningham SA, Kramer MR, Narayan KM. Incidence of childhood obesity in the United States. N Engl J Med 2014;370:403-11.

55 Zhang ZY, Wang MW. Obesity, a health burden of a global nature. Acta Pharmacol Sin 2012:33:145-7.

56 Morrato $E H$, Allison DB. FDA approval of obesity drugs: a difference in risk-benefit perceptions. JAMA 2012:308:1097-8.

57 Lagerros YT, Rössner S. Obesity management: what brings success? Therap Adv Gastroenterol 2013;6:77-88.

58 Kirk SF, Penney TL. The role of health systems in obesity management and prevention: problems and paradigm shifts. Curr Obes Rep 2013;2:315-9.

59 Katan MB. Weight-loss diets for the prevention and treatment of obesity. N Eng/ J Med 2009:360:923-5. 
60 Blundell JE, Stubbs RJ, Golding C, et al. Resistance and susceptibility to weight gain: individual variability in response to a high-fat diet. Physiol Behav 2005;86:614-22

61 Parkin DM, Boyd L, Walker LC. The fraction of cancer attributable to lifestyle and environmental factors in the UK in 2010. Br J Cancer 2011;105(Suppl 2):S77-81.

62 Espina C, Porta M, Schüz J, et al. Environmental and occupational interventions for primary prevention of cancer: a cross-sectorial policy framework. Environ Health Perspect 2013;121:420-6.

63 Schottenfeld D, Beebe-Dimmer JL, Buffler PA, et al. Current perspective on the global and United States cancer burden attributable to lifestyle and environmental risk factors. Annu Rev Public Health 2013;34:97-117.

64 Dartois L, Fagherazzi G, Boutron-Ruault MC, et al. Association between five lifestyle habits and cancer risk: Results from the E3N cohort. Cancer Prev Res (Phila) 2014:7:516-25.

65 Stewart BW, Wild CP. World Cancer Report 2014. Lyon: International Agency for Research on Cancer, 2014

66 World Health Organization. Public Health round-up. Countries need cancer prevention. Bull World Health Organ 2014;92:157.

67 Chalkidou K, Marquez P, Dhillon PK, et al. Evidence-informed frameworks for cost-effective cancer care and prevention in low, middle, and high-income countries. Lancet Oncol 2014;15:e119-31.

68 Moyer VA. Screening for lung cancer: U.S. preventive services task force recommendation statement. Ann Intern Med 2014;160:330-8.

69 Vineis P, Wild CP. Global cancer patterns: causes and prevention. Lancet 2014:383:549-57.

70 Jha P, Ramasundarahettige C, Landsman V, et al. 21st-century hazards of smoking and benefits of cessation in the United States. N Engl J Med 2013:368:341-50.

$71 \mathrm{Ng} \mathrm{M}$, Freeman MK, Fleming TD, et al. Smoking prevalence and cigarette consumption in 187 countries, 1980-2012. JAMA 2014;311:183-92.

72 Doll R, Peto R. The causes of cancer: quantitative estimates of avoidable risks of cancer in the United States today. J Nat/ Cancer Inst 1981;66:1191-308.

73 Varmus $\mathrm{H}$, Kumar HS. Addressing the growing international challenge of cancer: multinational perspective. Sci Trans/ Med 2013;5:175.

74 Rigotti NA. Smoking cessation in patients with respiratory disease: existing treatments and future directions. Lancet Respir Med 2013;1:241-50.

75 Holford TR, Meza R, Warner KE, et al. Tobacco control and the reduction in smoking-related premature deaths in the United States, 1964-2012. JAMA 2014;311:164-71.

76 Jha P. The 21st century benefits of smoking cessation in Europe. Eur J Epidemiol 2013;28:617-19.

77 Moyer VA; U.S. Preventive Services Task Force. Primary care interventions to prevent tobacco use in children and adolescents: U.S. Preventive Services Task Force recommendation statement. Ann Intern Med 2013:159:552-7.

78 Dunlop SM, Perez D, Cotter T. Australian smokers' and recent quitters' responses to the increasing price of cigarettes in the context of a tobacco tax increase. Addiction 2011;106:1687-95.

79 World Health Organization. WHO Report on the global tobacco epidemic. Enforcing bans on tobacco advertising, promotion and sponsorship. Luxembourg, 2013.

80 Thrift AP, Whiteman DC. Can we really predict risk of cancer? Cancer Epidemiol 2013:37:349-52

81 Smith SC Jr. Reducing the global burden of ischemic heart disease and stroke: a challenge for the cardiovascular community and the United Nations. Circulation 2011;124:278-9.

82 Lilly CL, Gebremariam YD, Cottrell L, et al. Trends in serum lipids among 5th grade CARDIAC participants, 2002-2012. J Epidemiol Community Health 2014;68:218-23.

83 Kontis V, Mathers CD, Rehm J, et al. Contribution of six risk factors to achieving the $25 \times 25$ non-communicable disease mortality reduction target: a modelling study. Lancet 2014 May 2. pii: S0140-6736(14)60616-4 doi: 10.1016/S01406736(14)60616-4. [Epub ahead of print]

84 Stephens S, Cobiac L, Veerman L. Improving diet and physical activity to reduce population prevalence of overweight and obesity: An overview of current evidence. Prev Med 2014;62:167-78.

85 James WP. Obesity - a modern pandemic: the burden of disease. Endocrinol Nutr 2013;60(Suppl 1):3-6.

86 Phillips G, Bottomley C, Schmidt E, et al. Measures of exposure to the Well London Phase-1 intervention and their association with health well-being and social outcomes. J Epidemiol Community Health, 2014:68:597-605.

87 Bourke M, Whittaker PJ, Verma A. Are dietary interventions effective at increasing fruit and vegetable consumption among overweight children? A systematic review. J Epidemiol Community Health 2014;68:485-90.

88 Laverack G. Improving health outcomes through community empowerment: a review of the literature. J Health Popul Nutr 2006;24:113-20.

89 O'Malley PG. On motivating patients: a picture, even if worth a thousand words, is not enough. Arch Intern Med 2012;172:309-10.

90 Smith SC Jr, Chen D, Collins A, et al. Moving from political declaration to action on reducing the global burden of cardiovascular diseases: a statement from the Global Cardiovascular Disease Taskforce. J Am Coll Cardiol 2013:62:2151-3.

91 Penney TL, Almiron-Roig E, Shearer C, et al. Modifying the food environment for childhood obesity prevention: challenges and opportunities. Proc Nutr Soc 2014;15:1-11.

92 Stark JH, Neckerman K, Lovasi GS, et al. Neighbourhood food environments and body mass index among New York City adults. J Epidemiol Community Health 2013:67:736-42.

93 Haughton B, Stang J. Population risk factors and trends in health care and public policy. J Acad Nutr Diet 2012;112(3 Suppl):S35-46.

94 Melendez Carrera P. The difficulty of making healthy choices and 'health in all policies'. Bull World Health Organ 2014;92:154.

95 Schmidt LA. New unsweetened truths about sugar. JAMA Intern Med 2014;174:525-6.

96 Martínez-González MA, Carlos S, de Irala J. [Human papillomavirus vaccine: optimism versus prudence]. Med Clin (Barc) 2008;131:256-63.

97 Haug CJ. Human papillomavirus vaccination-reasons for caution. N Eng J Med 2008:359:861-2.

98 Pons-Salort M, Thiébaut AC, Guillemot $\mathrm{D}$, et al. HPV genotype replacement: too early to tell. Lancet Infect Dis 2013;13:1012.

99 Hopkins TG, Wood N. Female human papillomavirus (HPV) vaccination: global uptake and the impact of attitudes. Vaccine 2013;31:1673-9.

100 Wise J. Young women most at risk are least likely to be offered HPV vaccine. BMJ 2014;348:g2190.

101 Garland SM, Brown DR. Potential of the quadrivalent human papillomavirus vaccine in the prevention and treatment of cervical cancer. Expert Opin Biol Ther 2014;14:527-34

102 Markowitz LE, Tsu V, Deeks SL, et al. Human papillomavirus vaccine introduction -the first five years. Vaccine 2012;30(Suppl 5):F139-48.

$103 \mathrm{Kim} \mathrm{JJ}$. The role of cost-effectiveness in U.S. vaccination policy. N Engl J Med 2011:365:1760-1.

104 Rose G. The strategy of preventive medicine. London: Oxford University Press, 1994

105 Stuckler D, Siegel K. Sick societies: responding to the global challenge of chronic disease. New York, NY: Oxford University Press, 2011.

106 Rodríguez-Rieiro C, Aragonés N, Pollan M, et al. Temporal trends of cervical cancer mortality rates among regions in Spain: 1975-2004. Med Clin (BarC) 2009;133:41-6. 